\title{
Special chapter on vacuum, microbalance and thermoanalytical techniques and hybrid nanocomposites and their applications
}

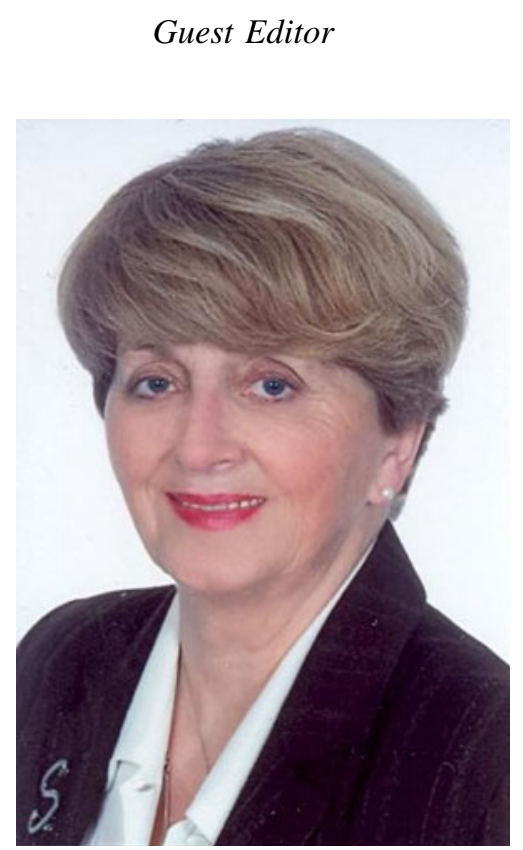

Prof. Zofia Rzączyńska

Faculty of Chemistry, Maria Curie-Sklodowska University,

M. Curie-Sklodowska Sq. 2, 20-031 Lublin, Poland

z.rzaczynska@ poczta.umcs.lublin.pl

This compilation is based on the materials of ICVMTT33 and 3rd Compositum. 